\title{
Truths and Misinformation: A Qualitative Exploration of Myotonic Dystrophy
}

\author{
Kori A. LaDonna, Amer A. Ghavanini, Shannon L. Venance
}

\begin{abstract}
Background: Myotonic dystrophy (DM1) is an autosomal dominant, progressive, and multisystem condition that impacts affected individuals physically, socially, and emotionally. Understanding individuals' perceptions of their disease is critical to ensuring appropriate information, education, and counseling. Methods: We conducted a content analysis of findings from a larger study that used a novel, qualitative research approach called photovoice to explore nine patients' experiences of living with DM1. Participants took pictures that illustrated barriers or facilitators to living with DM1; their photographs then formed the basis of semistructured interviews. Transcripts were analyzed and, among themes, we identified one titled "DM1 truths and misinformation" that described participants' disease knowledge. Analysis revealed four categories within this broader theme: "the physical and emotional cost of DM1," "managing my DM1," "genetics and me" and "patients as advocates and educators." Results: Findings showed that DM1 participants had good core knowledge with respect to their disease and its implications. However, each participant held as fact fragments of misinformation that shaped decisionmaking and pointed to a clear need for strategies to mitigate variable interpretation of health information. Conclusions: We conclude that there is a need for increased education and awareness about symptoms, genetic information and treatment strategies for patients, their family members, and health care providers.
\end{abstract}

RÉSUMÉ: Vérités et mésinformation : une exploration qualitative de la dystrophie myotonique. Contexte: La dystrophie myotonique (DM1) est une maladie plurisystémique progressive, à hérédité dominante, qui a un impact physique, social et émotionnel chez les individus qui en sont atteints. Il est très important de comprendre les perceptions qu'ont de la maladie les individus qui en sont atteints afin de leur fournir de l'information ainsi qu'un enseignement et des conseils appropriés. Méthode: Nous avons procédé à une analyse de contenu des observations d'une grande étude au moyen d'une approche de recherche qualitative novatrice, la méthodologie «Photovoice », pour explorer les expériences de 9 patients qui vivent avec la DM1. Les participants ont pris des photos qui illustraient les barrières ou les commodités qui leur facilitaient la vie avec la DM1; ces photographies ont ensuite servi de base à des entrevues semi-structurées. La retranscription de ces entrevues a été analysée et, parmi les thèmes abordés, nous en avons identifié un, « vérités et mésinformation sur la DM1 », qui décrivait les connaissances qu'ont les participants de la maladie. L'analyse a révélé quatre catégories à l'intérieur de ce thème plus vaste : « le coût physique et émotionnel de la DM1 », "gérer ma DM1 », « la génétique et moi » et « les patients comme défenseurs et éducateurs ». Résultats: Nous avons constaté que les participants atteints de DM1 avaient de bonnes connaissances de base concernant leur maladie et ses implications. Cependant, chaque participant ajoutait foi à des bribes de mésinformation qui affectaient leur processus décisionnel et mettait en évidence la nécessité d'établir des stratégies pour mitiger une interprétation variable de l'information sur la santé. Conclusions: Nous concluons qu'il existe un besoin d'informer et de sensibiliser davantage les patients, les membres de leur famille et les professionnels de la santé concernant les symptômes, l'information génétique et les stratégies de traitement de la DM1.

Keywords: Education, myotonic dystrophy, qualitative research

doi:10.1017/cjn.2015.26

Can J Neurol Sci. 2015; 42: 187-194

Myotonic dystrophy type 1 (DM1) - the most common adult muscular dystrophy-is a chronic, progressive, and life-limiting condition for which there are few treatments and no cure. DM1 is autosomal dominantly inherited and caused by a CTG repeat expansion in the 3' region of DMPK on chromosome $19 \mathrm{q} 13 .{ }^{1}$ DM1 is characterized by anticipation; consequently, subsequent generations experience earlier disease onset and greater symptom severity. ${ }^{2}$ In addition to distal extremity weakness, there is a variable occurrence of cardiac arrhythmias, respiratory impairment, dysphagia, apathy, cognitive deficits, endocrine abnormalities, cataracts, pain, and sleep disturbances. ${ }^{1}$ The multisystem clinical manifestations may impact the physical, emotional, and social function of affected individuals; in particular, disease severity, fatigue, cognition, and mood may impact DM1-affected individuals' health-related quality of life, ${ }^{3-5}$ family planning, and

From the Health \& Rehabilitation Sciences (KAL), Western University, Elborn College, London, ON Canada; Department of Medicine (AAG), University of Toronto,

Consultant, Credit Valley Hospital, Mississauga, ON, Canada; Department of Clinical

Neurological Sciences (SLV), Western University, University Hospital, LHSC, London, ON, Canada.

Received June 27, 2014. Final Revisions Submitted February 6, 2015.

Correspondence to: Shannon L. Venance, Department of Clinical Neurological Sciences, Western University, 339 Windermere Rd, University Hospital, LHSC, London, ON,

Canada N6A 5A5. Email: shannon.venance@lhsc.on.ca 
social and psychological health. ${ }^{6}$ A DM1 personality profile is emerging from the literature suggesting that those affected may have avoidant personality traits and cognitive impairment; it may therefore be difficult for individuals to participate in new activities or form relationships. ${ }^{7-9}$ A study of $200 \mathrm{DM} 1$ patients living in Quebec found that affected individuals had lower educational attainment, lower employment rates, and were more reliant on social assistance than the general population. ${ }^{10}$ Consequently, individuals with DM1 may experience disrupted social participation and dissatisfaction with their employment status, recreational pursuits, and mobility. ${ }^{11}$

The literature suggests that DM1 patients' variable symptom presentations may also challenge care provision. ${ }^{12,13}$ Furthermore, we speculate that health literacy_or "the degree to which individuals have the ability to obtain, process, and understand basic health information and services needed to make appropriate decisions"14 may be impacted for patients presenting with cognitive impairment, apathy, and low educational attainment. ${ }^{15}$ Previous research suggests that affected individuals have misunderstandings or misperceptions about $\mathrm{DM} 1^{16,17}$; in particular, an interview study with 25 DM1-affected women found that, although most participants had a good understanding of their DM1 symptoms, half of the sample misunderstood genetic information regarding anticipation and the potential risks associated with maternal transmission. ${ }^{16}$ Similarly, a questionnaire study of 200 DM1-affected individuals assessing their knowledge and attitudes about DM1 found that participants were less likely than non-affected participants to understand information about — and the consequences of-inheritance patterns and clinical manifestations. ${ }^{17}$

Individuals with low health literacy may be unable to understand information provided by their health care providers, including treatment advice and information about appointments. ${ }^{18}$ The doctor-patient relationship may be impacted because individuals may not understand information and may be unwilling or unable to ask for clarification; ${ }^{19}$ in turn, a survey study of approximately 1,500 patients with heart failure suggests that health literacy may impact an individual's ability and willingness to comply with treatment recommendations. ${ }^{19}$ Poor understanding about health information may also be associated with poorer health status and outcomes, increased hospitalization rates, ${ }^{20}$ and an increased risk for mortality. ${ }^{19}$ Given that DM1-affected individuals may miss clinic appointments or seem uninterested in their health, ${ }^{21}$ it is essential that researchers and clinicians assess patients' understanding of health information to ensure that they are able to actively participate in their care.

We speculate that patients' misperceptions and misinformation about their health may impede their ability to participate in shared decision-making. ${ }^{22}$ This is problematic because shared decision-making is widely considered to be the "pinnacle" of a patient-centered care approach ${ }^{23}$ that strives to use patients' needs, values, and goals to guide health management. ${ }^{24} \mathrm{We}$ contend that an understanding of DM1-affected individuals' knowledge and beliefs about their condition may directly impact patient-centered care approaches; that is, this information may be crucial for informing clinical care guidelines and for developing strategies for patient self-management. Therefore, exploring the health care perceptions of individuals living with DM1 is important for uncovering their understanding of DM1 to ensure that patients have the tools to proactively seek health information and manage their care.
Few studies have used qualitative research methods to explore symptom impact on affected individuals and their family members. ${ }^{13,25-29}$ We expect that an understanding of patients' experiences with-and knowledge about-DM1 will lead to better patient-centered care. We explored the experiences of individuals living with DM1 using photovoice-an innovative research methodology that uses participants' photographs to augment qualitative interviews. ${ }^{30-32}$ One theme identified from this study related to participants' knowledge about DM1. There was a mixture of fact and misperception that had the potential to impact their health and ability to make informed decisions and participate in shared-decision making. Therefore, the purpose of this analysis was to conduct an in-depth exploration of participants' understanding about DM1 and to identify knowledge gaps that may challenge patient-centered care provision.

\section{Patients and Methods}

Twenty-two individuals with mild to moderate adult-onset DM1 attending an academic neuromuscular clinic were purposively sampled and invited to participate in a study using photovoice to explore their experiences living with DM1; nine individuals $\left(\mathrm{n}=4\right.$ females) consented (Table 1). ${ }^{30}$ Reasons for declining participation included lack of time or interest and distance to travel. In addition, seven individuals expressing interest in participation were lost to follow-up contact.

\section{Data Collection: Photovoice}

Photovoice uses a visual image to document individual experience, and it is useful for conducting research with participants with low literacy or poor cognition. ${ }^{31,32}$ Photovoice has also been used to explore a variety of chronic neurologic conditions. ${ }^{33-37}$ Our photovoice study design incorporated three data collection components: a camera orientation session, an individual interview, and a focus group session. ${ }^{31,32} \mathrm{KAL}-\mathrm{a}$ graduate student who does not participate in the clinical care of DM1 individuals - conducted all information sessions and interviews with the participants.

After consenting, all nine participants attended an individual camera orientation session in which the purpose of the study was described, the ethics of picture taking was discussed, ${ }^{38}$ and participants were provided with a digital camera and instructed in its use. Participants were asked to "take pictures of what it is like to live with DM1," and to photograph barriers and facilitators to their health. Participants had two to three weeks to take pictures and then returned for an individual interview. Each individual interview was open-ended and participant-directed; that is, all nine participants began the interview by discussing his or her photographs. Probes such as: "Can you tell me about DM1?" were followed by questions pertaining to participants' disease history, symptoms, and daily activities. At the end of the individual interview, participants were asked to select two or three pictures to discuss during a focus group session. Five participants participated in one of two focus group sessions of two and three participants. Participant 2 withdrew from the study citing fatigue, and participant 3 did not attend her scheduled focus group session; their data were retained and analyzed. Participants 8 and 9 only participated in individual interviews; their data were intended as a "member check" 39 to ensure that the themes identified resonated with their experiences. We ceased recruitment when we determined that no new codes or themes were emerging, and that our 


\section{Table 1: Participant snapshots}

\begin{tabular}{|c|c|}
\hline Participant 1 & $\begin{array}{l}\text { Mid-50s and has mild DM1. Participant } 1 \text { asked her husband to assist with data collection; together, they took four pictures. She completed her individual } \\
\text { interview, but did not attend her scheduled focus group session. }\end{array}$ \\
\hline Participant 2 & $\begin{array}{l}\text { Early 70s and has mild-moderate DM1. Participant 2's husband helped her take pictures and he attended her individual interview. They discussed } 13 \\
\text { photographs. Although participant } 2 \text { was an enthusiastic research participant, she withdrew from the study because of fatigue. }\end{array}$ \\
\hline Participant 3 & Early 40 s and has moderate DM1. He took 15 pictures and participated in focus group 1. \\
\hline Participant 4 & Mid-40s and is moderately affected. He took 40 pictures and participated in focus group 1. \\
\hline Participant 5 & Early 40s and is mild-moderately affected. Participant 5 took 11 pictures and participated in focus group 2. \\
\hline Participant 6 & $\begin{array}{l}\text { Mid-40s and has moderate DM1. He was unable to take pictures because he had difficulty using the camera. Instead, his interview was structured around the } \\
\text { images he would have taken. Participant } 6 \text { participated in focus group } 2 .\end{array}$ \\
\hline Participant 7 & $\begin{array}{l}\text { Early 40s and has mild DM1. Participant } 7 \text { chose the subject matter of her } 28 \text { images, but her partner took the pictures on her behalf. Both participated in the } \\
\text { individual interview session, and participant } 7 \text { was a member of focus group } 2 \text {. }\end{array}$ \\
\hline Participant 8 & $\begin{array}{l}\text { Late 50s and has moderate DM1. Participant } 8 \text { stated that he had difficulty using the camera; consequently, he was only able to capture one image. Participant } \\
8 \text { 's individual interview was used as a member check of the preliminary findings. }\end{array}$ \\
\hline Participant 9 & Early 40 s and is mildly affected. Participant 9 took five photographs, and her individual interview was used as a member check of the preliminary findings. \\
\hline
\end{tabular}

data were therefore sufficient for providing a robust exploration of participants' experiences living with DM1.

\section{Data Analysis}

Participants were active collaborators in the data collection and analysis process; in particular, participants chose-and gave meaning to- the subject matter captured in their photographs. ${ }^{31,32}$ In turn, an inductive content analysis ${ }^{40}$ was used in which the authors coded the interview transcripts using words or phrases that described participants' actions or experiences. The most frequently occurring codes were collapsed into themes and categories. Of the nine themes identified, one related to participant knowledge of their disease coded as DM1: "Truths and Misinformation," captured passages describing patients' knowledge or misconceptions about the etiology, inheritance patterns or symptoms of DM1. To provide a deeper exploration of this theme, two neuromuscular clinicians (SLV and AAG) reviewed and coded these passages using words or phrases that described the topic being discussed (e.g. "genetics" or "symptom impact"), then labeled them as a "truth" (i.e. "good" understanding) or as "misinformation." KAL then reviewed and consolidated the codes into themes. All researchers met regularly to discuss the codes and themes and to resolve areas of discrepancy; in particular, discrepant issues were resolved with discussion and/or by reviewing the patients' transcript in tandem with their chart. The final list of themes was developed by consensus. NVivo@, a qualitative research software program, was used to organize and manage the data. To enhance the study's relevance and resonance for clinicians, we conducted a retrospective chart review to collect demographic and clinical information (Table 2).

The study was approved by the Western University Research Ethics Board, London, Ontario, Canada.

\section{RESUlts}

All patients had been symptomatic for many years (range 8-34 years, mean \pm standard error of the mean $19.2 \pm 3$ years) before participating (Table 2). Seven of the nine participants had a family history of DM1, and all but one were ambulatory. In general, all participants discussed DM1 symptoms and their impact on daily life with varying degrees of certainty. Yet, all participants stated as fact opinions that reflected misperceptions on the part of self, friends, family, family physicians, specialists, and others. Four themes were identified: "the physical and emotional cost of DM1," "managing my DM1," "genetics and me," and "patients as advocates and educators."

\section{Physical and Emotional Costs of DM1}

All participants were aware of the variable presentation and progressive nature of DM1 and were able to accurately describe neuromuscular and systemic manifestations. Participants were often knowledgeable about symptoms and disease complications regardless of whether they had experienced them personally. In particular, patients correctly identified weakness, droopy eyelids, fatigue, myotonia, sleep abnormalities, pneumonia, diabetes, cataracts, and cardiac abnormalities as complications of the disorder.

\section{Table 2: Clinical and demographic background of the participants}

\begin{tabular}{l|c}
\hline Duration of disease at time of study & $19.2 \pm 3$ years \\
\hline Age of symptom onset & $27.6 \pm 4.5$ years \\
\hline Time to diagnosis & $5.4 \pm 2.9$ years \\
\hline Postsecondary education & $2 / 9(22 \%)$ \\
\hline Employed & $2 / 9(22 \%)$ \\
\hline Family member with DM1 & $7 / 9(78 \%)$ \\
\hline Number of trinucleotide repeats & $793 \pm 38$ \\
\hline Ptosis & $7 / 9(78 \%)$ \\
\hline Dysphagia/dysarthria & $7 / 9(78 \%)$ \\
\hline Respiratory involvement & $5 / 9(55 \%)$ \\
\hline Weakness & $9 / 9(100 \%)$ \\
\hline Ambulatory & $8 / 9(89 \%)$ \\
\hline Diabetes & $2 / 9(22 \%)$ \\
\hline Cataracts & $6 / 9(67 \%)$ \\
\hline Cardiac involvement & $4 / 9(44 \%)$ \\
\hline Depression & $3 / 9(33 \%)$ \\
\hline Excessive daytime sleepiness & $6 / 9(67 \%)$ \\
\hline
\end{tabular}




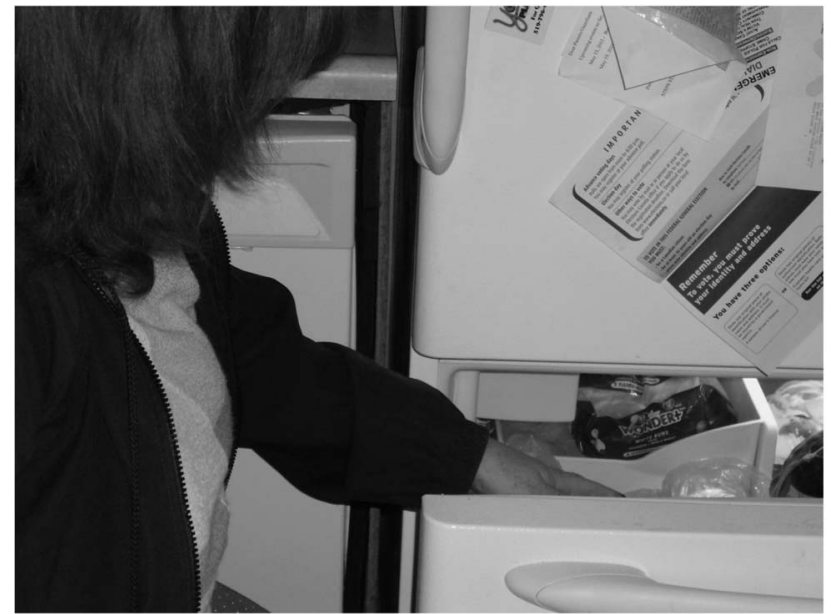

Figure 1: Physical and emotional costs of DM1: the challenges of everyday activities. When asked what household chores she had difficulty with, participant 7 responded: "Everything. Actually, vacuuming...Getting places to do the dusting and whatnot, depending on how much room there is. I can't stand for long periods. I had to get a new fridge where the freezer was on the bottom so I could reach down into it, it's a drawer type. It makes it much easier to get things."

\begin{abstract}
"You got muscles. Like my heart's a muscle and since I have heart disease, I said where'd that come from? Myotonic dystrophy they told me. And that affected my muscle and my heart so they had to put in a pacemaker to pace it. But like I said, what's going to happen eventually? They just keep putting in a new thing every ten years or whatever and after that they just said, it just stays in until you die I guess." (participant 1)
\end{abstract}

Occasionally, participants did not relate symptoms or consequences (e.g. excessive daytime sleepiness or ptosis) to their DM1, or they stated that potentially unrelated symptoms were caused by DM1. For example, participant 2 identified a "cough" that was chronic - and clearly unrelated to her DM1-as the symptom that led her to believe she had inherited the disease from her father: "On my mother's side there is no one. No one. It was dad and I know that because I nursed dad and I was the oldest girl and I was a nurse. So anyway, we spent a lot of time at their house. Dad got this cough and he would almost whoop. Well I have that...." (participant 2)

The physical and emotional burden of DM1 on participants was significant (Figure 1), and participants articulated their grief for lost function, limited social and employment opportunities, and the ability-largely attributed to inheritance and the understanding of genetics - to have children. Moreover, participants had insight that DM1 affected their physical appearance, resulting in body image concerns. These concerns were magnified by perceptions that the general public's lack of awareness about DM1 contributed to judgmental behavior.

\footnotetext{
"The main problem I have with this is not something you can see because a lot of people don't understand. Like, if you don't have an arm, okay, they figure that out. You know, if you don't have a foot or you have to wear shades, fine, but
}

you can't see the myotonic dystrophy, and people judge. But it bothers me the most with (son with DM1) because they judge a person's intelligence by their speech. Son's speech is not the clearest so they assume he's not the brightest, and he knows they assume he's not the brightest because of his speech, so that bothers me.” (participant 9)

Participants correctly perceived the likelihood of progressive disability over time, but there was a "crystal ball" mentality in which participants envisioned that worst-case scenarios were inevitable. Participant 8 described his concerns about needing assistance in the near future: "Probably as my disease starts deteriorating. My hands-you know, pretty soon I won't be able to do anything and I'll go to a nursing home." Finally, some participants were aware of the early mortality that is associated with DM1 when symptoms present in adolescence or early adulthood: "Because, like people with myotonic dystrophy do have a shorter lifespan. Usually late $50 \mathrm{~s}, 56$ and up usually is when... Not necessarily that you hit 56 and you die. But you're still going to get worse and probably be in bed more and stuff like that." (participant 3)

\section{Managing My DM1}

Participants understood that although DM1 is currently without treatments that slow disease or provide a cure, there are a variety of strategies available for symptomatic management. The need for multidisciplinary care was acknowledged, and participants were able to identify dietary management, feeding tubes, bilevel positive airway pressure (BiPAP) machine, mobility devices, and regular monitoring for cataracts and cardiac care as important strategies for managing DM1. However, some participants engaged in a variety of self-care strategies of variable efficacy:

"I am on a BiPAP machine but only during the night...I feel I need it because it is easier to breathe with it on...Because I have an air purifier, it takes all the toxins out of the air and you get pure air and that takes away, that I don't have to wear that because the pure air is there. I still wear the thing at night but the pure air is in the rooms all where I live so it's just pure air and it's clean, it's fresh and it's good, good for the body." (participant 6)

Furthermore, participant 7 stated that her cough assist device improved her swallowing difficulties, and others believed that strenuous exercise was detrimental and should be avoided. Several participants, however, described that staying active could be beneficial; for instance, participant 9 encouraged her affected children to be physically active because she erroneously believed that exercise would make them stronger, reverse their muscle weakness and atrophy, and improve function:

"You know... there's no reason why my kids can't be great at karate even though they have muscle weakness. That's part of why they're in karate is to strengthen their muscles so when their muscles do let them down, they have more muscle memory than the average so they'll buck up to normal." 


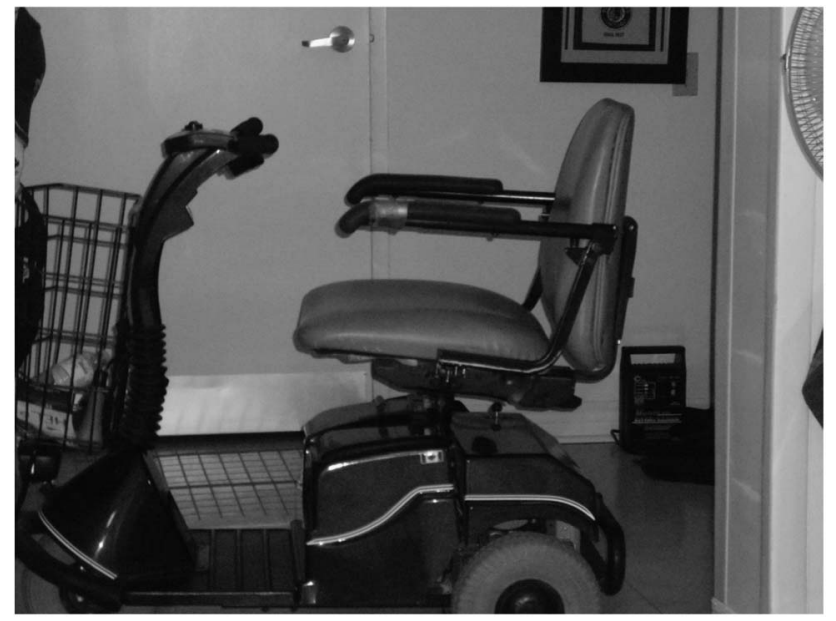

Figure 2: Managing my DM1: using a mobility device to navigate public spaces. "That's my scooter, that's very helpful. My hot rod.... So, yeah, I just use it to go the library or just to go to downtown or whatever, the mall, around the building...it helps me a lot" (participant 4).

Finally, some participants articulated the rationale for being unable to drive because of excessive daytime sleepiness or muscle weakness, and compensated by arranging transportation through friends and family or by using mobility devices such as scooters (Figure 2), wheelchairs, or canes.

\section{Genetics and Me}

All participants described that DM1 was an inherited disease, but participants' knowledge about genetics was unpredictable. Therefore, although some participants were well- informed about genetics, most described some incorrect information. In particular, participants did not accurately describe genes, inheritance patterns, and the relationship of gender to the disease. Although these beliefs were accepted as fact, it was also clearly apparent that participants had grappled with, and tried to make sense of, this very complex topic. In an effort to describe genetics to her child, one participant likened DM1 to a "broken stair" in the DNA structure.

\begin{abstract}
"On one of the floors on (science museum) they have the double helix, so I was demonstrating to (daughter), this is what the helix looks like, and this, and I broke apart the stairs, is what ours looks like because that's where the myotonic dystrophy is, so she understands that. So that's what the myotonic dystrophy is, a broken stair in our spiral staircase." (participant 9)
\end{abstract}

Participants were able to describe anticipation and the severity of a childhood presentation of DM1, yet misconstructions about inheritance were common. One participant stated that the likelihood of an affected sibling having an unaffected child was "slim," another described that there was only a $25 \%$ chance of passing the gene on, and several incorrectly described the effect of gender on inheritance: “... they say mother to son, and son to daughter. It seems to go that way. My sister thought it goes from mother to daughter. I said not. Most of the kids I seen it comes from the father to the daughter and vice versa for the father." (participant 1)
Moreover, participant 2 expressed surprise (perhaps understandably) that all of her children were affected because she believed that autosomal dominant inheritance meant that only half of her children would inherit the gene: "I am sorry all of my children have it. This was supposed to be 50\%." DM1 "skipping generations" was also reported; participant 3 stated that his sister had undergone genetic testing and tested negative, yet he was concerned that his sister's children might still inherit DM1: "Um, like they tested my sister and she's fine... So, my sister's fine. Don't know if her children are going to have it but they're too young to test right now. They gotta be at least in their teens and they're not there yet. But they can have it."

Participants also stated that gender influenced disease severity and progression; they believed that men were more likely to inherit and that DM1 progressed faster in males. However, one participant believed that the disease was more severe in females, yet did not attribute this to the risk of having a severely affect child with congenital onset. Knowledge of genetics and inheritance-influenced decisions around family planning was inconsistent. In some cases, reproductive decisions were made before diagnosis. However, two participants decided not to have children after confirmation of their diagnosis to prevent passing the gene to their children. Participant 6 had considered anticipation, and understood that he could have a severely affected child: "Because I was told that if had a child with my wife, it could be delivered with it [DM1] and so I said, 'I can't do that, I can't do it, I wouldn't do it.' It's unfortunate I can't have a child but it's just not a good idea."

However, although others understood the concept of inheritance, they did not fully comprehend the risk:

\begin{abstract}
"Like I mean apparently they've found the gene that does it. That's the normal gene or whatever, ours is this. That's as far as I know about it, that it's mutated. If you have two of the little ones, you're good. But I've got one of each, so it's only $25 \%$ my kids will get it. It's not like my partner has it. She has two normal ones, so it's $75 \%$ chance he's going to be normal." (participant 5)
\end{abstract}

\section{Patients as Advocates and Educators}

Participants identified that the relative rarity of DM1 meant that neither the general public, nor most health care providers, were particularly knowledgeable about the condition. Participants took it upon themselves to take leadership roles in the DM1 community (participant 4) or to educate themselves, their health care providers, or other stakeholders about DM1. For example, participant 3 visited a Masters of Occupational Therapy class to educate students about his experiences, and participant 5 was aware that patient education resources were available. However, he stated that the medical language was daunting: "I mean I can read Harper's book, but there's stuff there that is beyond me. My doctor understood it, but then that's his language. I don't speak that language." However, participants also recognized that these resources were beneficial for their nonneuromuscular health care providers, and participants depended on specialists to distil complex information:

"As I said, I gave him [family physician] that Harper book and he went to town with that, and then he found as much as he could on his Blackberry. But he had never come across it, 
at least not myotonic. I'm sure he's seen or heard about [muscular dystrophy], but not the myotonic. But, yeah, he found as much as he could." (participant 5)

Participants also discussed that there was limited clinical or pharmacological research available for DM1, particularly in comparison to other neurological illnesses. Participants, however, were engaged in, and advocated for, more basic science or patientcentered research:

\begin{abstract}
"Well I like to see things get better in the health care field for people with what I have and other people have what they have. Because like you said, there is no medication for us with this disease, they're working on that, I hope they find something.... So I'm here to try to help them the best I can, that's why I'm here (participating in research)...it's my health. I want to do what I can." (participant 6)
\end{abstract}

\section{DISCUSSION}

We examined the DM1-specific knowledge of individuals who were part of a larger qualitative research study that explored the experience of living with DM1. Findings revealed that DM1 participants had reasonable core knowledge with respect to their disease and its implications. However, each participant held as fact fragments of misinformation that often shaped decisionmaking. We suggest that care cannot be "patient-centered" if patients do not have the correct information to make informed health care decisions. Therefore, we identified a clear need for strategies to mitigate variable interpretation of health information. Our findings have implications for the health literacy of - and patient-centered care provision for-DM1; in particular, DM1-affected individuals' knowledge gaps need to be addressed to optimize their ability to participate in shared decision-making.

Study participants were able to knowledgably describe many of the multisystem complications of DM1. It is possible that patients learn the clinical manifestations of the disease through their lived experience. Twenty-five participants with affected children had more knowledge of the disease than subjects without affected children, suggesting that experience rather than counseling may drive patient knowledge. ${ }^{16}$ However, participants sometimes misattributed the causality of symptoms such as excessive daytime sleepiness, and used their own strategies such as increasing caffeine intake to try and ameliorate fatigue. These findings resonate with studies that have examined the knowledge and perceptions of individuals with DM1. ${ }^{16,17}$ Of the 200 individuals who completed a DM1 knowledge assessment questionnaire, $30.5 \%$ believed that they had a poor grasp of disease-specific information. ${ }^{17}$ In particular, affected individuals were less likely than noncarriers to recognize that physical limitations, apathy, learning difficulties, and decreased social and employment opportunities were potential implications of DM1. ${ }^{17}$ Importantly, patients with a number of neuromuscular diseases considered a lack of information about their condition more concerning than their degree of disability. ${ }^{41}$

Genetics was the theme most frequently identified with inaccuracies in interpretation for participants in the present study, although we recognize that this study was distant from any genetic counseling participants might have received. Nevertheless, this finding is consistent with the literature. Faulkner et al interviewed 25 reproductive-age women with DM1 and found that participants had a sound knowledge of DM1 symptoms, yet only $56 \%$ of the subjects were able to describe the risk of transmission correctly. ${ }^{16}$ Similarly, Laberge et $\mathrm{al}^{17}$ found that half of the 200 DM1 patients surveyed did not have a thorough understanding of the mode of inheritance. In the present study, in addition to difficulties describing the inheritance pattern, there were expressed beliefs that gender influenced both inheritance and disease progression. Although participants accurately described anticipation, the increased risk of a severely affected infant was not ascribed to maternal inheritance. This finding has implications for clinical care because all participants had received information from patient education resources, either in the neuromuscular clinic or from genetic counselors following a genetics referral. However, this is perhaps not surprising given that findings from other qualitative research studies suggest that variable knowledge about genetics is common in other chronic disease populations. $^{42,43}$

We speculate that the intra- and inter-individual variability of disease expression within families over time with mildly symptomatic or asymptomatic relatives in previous generations contributes to the confusion regarding inheritance. Another potential explanation is an interaction between mild cognitive impairments in DM1-affected individuals and the complexity of genetic concepts, which are often not revisited in a systematic way in the clinic after initial discussions around diagnosis and inheritance. Cognitive deficits associated with DM1 have been described, ${ }^{9,21}$ and we speculate this may explain some of the knowledge gaps in a general population of DM1 patients. In patients with DM1, each additional 100 CTG repeats reduced the odds of answering questions on the mode of inheritance correctly by $18 \% .{ }^{17}$ Subtle cognitive impairment, however, may remain undetected on routine clinical assessment in the absence of the application of specific assessment tools such as the Montreal Cognitive Assessment.

Regardless, the participants in the present study were active and engaged research participants who perceived themselves as educators and advocates. Participants were able to articulate a number of common disease features with good insight into how symptoms impacted their daily lives. It may be inappropriate to attribute misperceptions solely to cognition; instead, other factors including (1) the variable presentation of symptoms in other family members, (2) a large amount of complex information being given to patients during time-limited clinic appointments, and (3) a lack of "checking" on the part of health care providers to ensure that participants are retaining appropriate information may contribute to patients' variable understanding of complex health information.

To address these factors, we suggest that patients would benefit from follow-up appointments at regular intervals with review and assessment of relevant knowledge and the opportunity to ask and answer questions that facilitate engagement with shared decision-making. We recognize, however, that traditional, physician-led clinical care models may be impeded by system capabilities - including time-limited appointments-from fulfilling this need. Others have suggested that a more holistic or multidisciplinary clinical approach may be useful for addressing DM1-affected individuals' complex needs. ${ }^{12,44,45}$ We therefore 
suggest that patients would benefit from referral to nurses and other allied health professionals familiar with myotonic dystrophy -including social workers and occupational therapists-for further clarification about symptoms or general disease-specific information, to assist patients in decision-making, and to provide reassurance, particularly in regard to disease progression and genetic information. Counseling and educational interventions may improve patient knowledge in this category. ${ }^{46}$ It is likely that this information sharing will be an ongoing process to ensure adequate comprehension, retention of information, and application to relevant decision-making over the disease course. Anecdotally, we hosted a DM1 patient education day in which patients not only had the opportunity to learn about the latest DM1-related information and research from various health care providers, but they were also able to share common experiences with others with DM1. Given that one participant in the present study found the language of patient education resources to be difficult to understand, a patient education day is a good opportunity for health care providers to simplify and clarify a wide range of health information.

\section{Limitations and future directions}

This is a small study that reported on the experiences of nine patients living with DM1. Findings, therefore, are not generalizable, but they may resonate with DM1-affected individuals and clinicians in other settings. Similarly, we did not set out to evaluate the health literacy of DM1-affected individuals; instead, findings pertaining to disease knowledge were identified during data analysis of participants' photographs and narratives regarding their experiences living with DM1. Therefore, future research questions could be directed at the health literacy assessment of individuals with DM1 that can then be used to develop interventions and patient education materials. In turn, qualitative interviews with patients would be useful for assessing the content, readability, and applicability of any education or research materials. It may also be advantageous to examine current DM1 clinical care models to determine if they are meeting patients' complex physical, psychosocial, and educational needs.

Importantly, we identified that some participants felt responsible for educating nonneurology specialists about DM1. It may therefore be important not only to assess and clarify patients' knowledge, but also to provide in-services, one-page "DM1 fact sheets" for family and generalist physicians, or to give presentations to other specialties to ensure that accurate information is disseminated to health professionals caring for individuals with DM1. Patients may be a powerful and underused resource for raising awareness in the clinical setting.

\section{CONCLUSION}

Although patients are knowledgeable about DM1, they have misinformation and misperceptions that may affect their ability to make important decisions about their health. Findings suggest that information about genetics is particularly problematic for patients, and that misinformation may influence decision-making. Therefore, future research should address the educational needs of patients; in turn, educational interventions are required to bridge these health literacy gaps and optimize the health and decisionmaking capabilities of patients with DM1.

\section{ACKNOWLEDGEMENTS}

The views expressed in the submitted article are the authors and not an official position of the institution or funder. We would like to acknowledge and thank the participants for sharing their experiences with us. We would also like to thank Betsy Toth and Christine Piechowicz for their assistance with study coordination.

This research was generously supported by the Western University Department of Clinical Neurological Sciences Internal Research Fund.

\section{Disclosures}

Shannon Venance has the following disclosures: Genzyme Canada, CME talks on muscle disease, and speaker's fees. Amer Ghavanini and Kori LaDonna have nothing to disclose.

\section{REFERENCES}

1. Udd B, Krahe R. The myotonic dystrophies: molecular, clinical, and therapeutic challenges. Lancet Neurol. 2012;11:891-905.

2. Arsenault ME, Prévost C, Lescault A, Laberge C, Puymirat J, Mathieu J. Clinical characteristics of myotonic dystrophy type 1 patients with small CTG expansions. Neurology. 2006;66:1248-50.

3. Antonini G, Soscia F, Giubilei F, et al. Health-related quality of life in myotonic dystrophy type 1 and its relationship with cognitive and emotional functioning. J Rehabil Med. 2006;38:181-5.

4. Laberge L, Mathieu J, Auclair J, Gagnon E, Noreau L, Gagnon C. Clinical, psychosocial, and central correlates of quality of life in myotonic dystrophy type 1 patients. European Neurology. 2013;70:308-15.

5. Peric S, Rakocevic-Stojanovic V, Stevic Z, et al. Health-related quality of life in patients with myotonic dystrophy type 1 and amyotrophic lateral sclerosis. Acta Neurol Belg. 2010;110:71-7.

6. Boström K, Nätterlund BS, Ahlström G. Sickness impact in people with muscular dystrophy: a longitudinal study over 10 years. Clin Rehabil. 2005;19:686-94.

7. Delaporte C. Personality patterns in patients with myotonic dystrophy. Arch Neurol. 1998;55:635-40.

8. Meola G, Sansone V, Perani D, et al. Executive dysfunction and avoidant personality trait in myotonic dystrophy type 1 (DM-1) and in proximal myotonic myopathy (PROMM/DM-2). Neuromusc Disord. 2003;13:813-21.

9. Sistiaga A, Urreta I, Jodar M, et al. Cognitive/personality pattern and triplet expansion size in adult myotonic dystrophy type 1 (DM1): CTG repeats, cognition and personality in DM1. Psychol Med. 2010;40:487-95.

10. Laberge L, Veillette S, Mathieu J, Auclair J, Perron M. The correlation of CTG repeat length with material and social deprivation in myotonic dystrophy. Clin Genet. 2007;71:59-66.

11. Gagnon C, Mathieu J, Noreau L. Life habits in myotonic dystrophy type 1. J Rehabil Med. 2007;39:560-6.

12. Gagnon C, Noreau L, Moxley RT, et al. Towards an integrative approach to the management of myotonic dystrophy type 1 . J Neurol Neurosurg Psychiatry. 2007;78:800-6.

13. Heatwole C, Bode R, Johnson N, et al. Patient-reported impact of symptoms in myotonic dystrophy type 1 (PRISM-1). Neurology. 2012;79:348-57.

14. Medicine Io. Health literacy: a prescription to end confusion. Washington, DC: National Academies Press; 2004.

15. Censori B, Danni M, Del Pesce M, Provinciali L. Neuropsychological profile in myotonic dystrophy. J Neurol. 1990;237:251-6.

16. Faulkner CL, Kingston HM. Knowledge, views, and experience of 25 women with myotonic dystrophy. J Med Genet. 1998;35: 1020-1025.

17. Laberge L, Prévost C, Perron M, et al. Clinical and genetic knowledge and attitudes of patients with myotonic dystrophy type 1. Public Health Genom. 2010;13:424-30.

18. Schloman B. Health literacy: a key ingredient for managing personal health. Online J Issues Nurs. 2004;9:7. 
19. Peterson PN, Shetterly SM, Clarke CL, et al. Health literacy and outcomes among patients with heart failure. JAMA. 2011;305: $1695-1701$.

20. Williams MV, Davis T, Parker RM, Weiss BD. The role of health literacy in patient-physician communication. Family Med. 2002;34:383-9.

21. Meola G, Sansone V. Cerebral involvement in myotonic dystrophies. Muscle Nerve. 2007;36:294-306.

22. Charles C, Gafni A, Whelan T. Shared decision-making in the medical encounter: what does it mean? (or it takes at least two to tango). Social Sci Med. 1997;44:681-92.

23. Barry MJ, Edgman-Levitan S. Shared decision making: pinnacle of patient centered care. New Engl J Med. 2012;366:780-1.

24. Institute of Medicine. 2014 [cited 2014 October 26]; Available from: http://iom.edu/Reports/2001/Crossing-the-Quality-Chasm-A-NewHealth-System-for-the-21 st-Century.aspx

25. Bostrom K, Ahlstrom G. Quality of life in patients with muscular dystrophy and their next of kin. Int J Rehabil Res. 2005;28:103-9.

26. Bostrom K, Ahlstrom G, Sunvisson H. Being the next of kin of an adult person with muscular dystrophy. Clin Nurs Res. 2006;15:86-104.

27. Cup EHC, Kinebanian A, Satink T, et al. Living with myotonic dystrophy; what can be learned from couples? A qualitative study. BMC Neurol. 2011;11:86-98.

28. Boström K, Ahlström G. Living with a chronic deteriorating disease: the trajectory with muscular dystrophy over ten years. Disabil Rehabil. 2004;26:1388-98.

29. Geirdal AO, Lund-Petersen I, Heiberg A. Understanding the experience of myotonic dystrophy. Mixed method study. J Genet Couns. 2015;24:169-78

30. LaDonna KA, Venance SL. Picturing the experience of living with myotonic dystrophy (DM1): a qualitative exploration using photovice. Manuscript submitted; 2014.

31. Wang C, Burris MA. Empowerment through photo novella: portraits of participation. Health Educ Behav. 1994;21:171-86.

32. Wang C, Burris MA. Photovoice: concept, methodology, and use for participatory needs assessment. Health Educ Behav. 1997;24:369-87.

33. Levin T, Scott BM, Borders B, Hart K, Lee J, Decanini A. Aphasia talks: photography as a means of communication, self-expression, and empowerment in persons with aphasia. Topics Stroke Rehabil. 2007;14:72-84.

34. Lorenz LS, Kolb B. Involving the public through participatory visual research methods. Health Expectations. 2009;12:262-74.

35. Aubeeluck A, Buchanan H. Capturing the Huntington's disease spousal carer experience: a preliminary investigation using the 'Photovoice' method. Dementia. 2006;5:95-116.

36. Wiersma EC. Using Photovoice with people with early-stage Alzheimer's disease: a discussion of methodology. Dementia. 2011;10:203-16.

37. Guerra SR, Rodrigues SP, Demain S. Evaluating profamiliesdementia: adopting photovoice to capture clinical significance. Dementia. 2013;12:569-87.

38. Wang CC, Redwood-Jones Y. Photovoice ethics: perspectives from Flint photo voice. Health Educ Behav. 2001;28:560-72.

39. Lincoln YS, Guba EG. Naturalistic inquiry. Newbury Park, CA: Sage; 1985.

40. Miles MB, Huberman AM, Saldana J. Qualitative data analysis: a methods source book, 3rd ed. Thousand Oaks, CA: Sage; 2014.

41. Abresch RT, Seyden NK, Wineinger MA. Quality of life: issues for persons with neuromuscular diseases. Phys Med Rehabil Clin N Am. 1998;9.

42. McKibbin M, Ahmed M, Allsop MJ, et al. Current understanding of genetics and genetic testing and information needs and preferences of adults with inherited retinal disease. Eur J Hum Genet. 2014:1-5.

43. Saukko PM, Ellard S, Richards SH, Shepherd MH, Campbell JL. Patients' understanding of genetic susceptibility testing in mainstream medicine: qualitative study on thrombophilia. BMC Health Serv Res. 2007;7:82.

44. Gagnon C, Chouinard MC, Lavoie M, Champagne F. [Analysis of the nursing role in the care of patients with neuromuscular disorders]. Can J Neurosci Nurs. 2010;32:22-9.

45. Gagnon C, Chouinard MC, Laberge L, et al. Health supervision and anticipatory guidance in adult myotonic dystrophy type 1 . Neuromuscul Disord. 2010;20:847-51.

46. Furr LA, Kelly SE. The genetic knowledge index: developing a standard measure of genetic knowledge. Genet Testing. 1999;3: 193-199. 